\title{
Gender Differences in The Use of Internet for Health Information Search
}

\author{
Bahar YAŞIN' ${ }^{1}$, Hilal ÖZEN²
}

\begin{abstract}
Demand for health related information is expanding. People seeking health information have many options today. Internet is becoming an important source of information for health related activities in recent years because of its convenience and large capacity. The use of Internet in Turkey increased dramatically from 13 percent users in 2004 to 30 percent in 2009. National survey conducted by the Turkish Statistical Institute in 2007 shows that 37 percent of Turkish people used the Internet for online health related information. Once consumers enter the domain of electronic health care information, the issue becomes determining the quality of the available information. How do consumers perceive the quality of online health information? This study addresses gender differences in Turkish consumer's perceptions regarding the quality of electronic health information on web sites. Research results showed that males and females differ by their e-health information quality perceptions. Main discriminating issues of males and females are related to helpfulness and safety of the online health information. Females are found to have higher e-health information quality perception than males.
\end{abstract}

Keywords: Electronic Health Information, Internet, Gender, Discriminant Analysis, Turkey.

\section{INTRODUCTION}

Use of the Internet is growing everywhere and it has become an increasingly popular resource for consumers. It is no longer merely a source of information or communication, but offers useful platforms for consumers to conduct a variety of activities (Dolan et al., 2004). A recent survey in England found that about half of consumers now actively use the Internet to order tickets, goods or services (Office of $\mathrm{Na}$ tional Statistics, 2003). In Turkey, consumers use the Internet mostly for e-mailing (72.4\%), reading newspapers $(70 \%)$ and chatting (57.8\%) (TUIK, 2009). Even, e-mailing is still one of the most popular uses of the Internet; consumers use it also to access health related information. The Internet has become the biggest medical library in the world and it is likely to play a key role in future healthcare related communication (Akerkar and Bichile 2004, Dumitru et al., 2007, Hussain et al., 2004). The recent results of the Turkish Statistical Institute's ICT (Information Communications Technology) Usage in Households survey estimated that more than 45 percent of Turkish Internet users searched for health information online in 2009.

Many studies in the field of health information focus on the quality of medical information that patients obtain from the Internet (Eysenbach and Diepgen, 1998, Khechine et al., 2008, Risk and Petersen, 2002). Other research investigates patients' needs when they look for information on the Internet. Eysenbach and Diepgen (1999) analyzed the motivations, expectations, and misconceptions of patients seeking teleadvice or medical information on the Internet. Shuyler and Knight (2003) examined the most frequent reasons visitors look for medical websites. Khechine, Pascot, and Prémont (2004a) addressed the question of information needs for French-speaking patients. Gruca and Wakefield (2004) evaluated the information given in web sites of 111 hospitals and found quality of providing information inadequate in most of the websites.

On the basis of the literature, the current study mainly attempts to address whether there are any differences between the electronic health (e-health) information quality perceptions of males and females.

\section{CONCEPTUAL BACKGROUND}

Consumers seeking information about health related issues have more options today than they had in the past. Available technology provides customers with more outlets to seek information 
(Goetzinger et al., 2007). The Internet is one of the biggest information search alternative and is likely to play a key role in future healthcare related communication (Akerkar and Bichile 2004, Dumitru et al., 2007, Hussain et al., 2004). It is a source of information at our fingertips with health information being no exception (Goetzinger et al., 2007). It has transformed the way many health seekers find health information and has completely changed consumers' decision-making process, particularly within the health care industry. The number of people using the Internet has exponentially increased in recent years and the Internet has become a favored source to find health information (Dumitru et al., 2007). Worldwide, about 4.5 percent of all the Internet searches are for health related information (Morahan-Martin 2004). In Turkey, 37 percent (TUIK, 2007) of Internet users search for health related information.

The use of the Internet by patients for health purposes have been examined in many studies (Khechine et al. 2008). For instance, Lueg, Moore and Warkentin (2003) tried to understand how Internet users search for and benefit from the Internet health information. They observed a relationship between the frequency of Internet use and the short-term (communication) effects and long term (life benefits) effects on patients. Dolan et al. (2004) sought to evaluate patients' use of the Internet information in a primary care setting. One of their results is that the use of online health related information makes most patients feel more prepared and able to participate in decision-making about treatments. Nustad, Adams and Moore (2008), examined and compared sources of health-related information accessed by female college students with and without body image distortions and the believability of those sources. They found that the internet was the second most popular source for seeking health information; however, the believability of the Internet was found relatively low. Many other investigations attempts to assess the relationship between the Internet use by patients and health outcomes. For instance, Dickerson et al., (2004) found that almost half of their sampled patients reported that the information obtained online was unrelated to their clinical visits. Khechine, Pascot and Prémont (2004b) argue in support of the existence of a positive relationship between the use of Internet information by patients and the consumption of healthcare resources.

\subsection{Internet as a Source of Health Information}

Health information is more and more available on the Internet, with the continuous growing of medical information websites. While many of them are for health professionals, more and more websites directly address the population with a view of providing information about health problems, self-care and prevention (Benigeri and Pluye, 2003). Consumers now have access to scientific evidence, educational materials, online doctors, off shore pharmacies, support groups, chat rooms, and online counseling (Paris and Ferranti, 2001). With increased ease of access to the Internet and health care information becoming readily available, consumers are demanding access to medical information 24 hours a day and want to be able to contact, ask questions and chat with their physicians (Cudore and Bobrowski, 2003).

Internet content covers a broad range of topics related to health. Some diseases and treatments such as those related to chronic illnesses remain the most popular on the Internet (Khechine et al., 2008). Many factors contribute to the growth of the interest of individuals in the Internet as a major source of health information. First, health related websites supply more content that satisfies patients' needs and helps to create new needs. Second, patients are more educated and aware of the necessity to prevent health problems and to rely on themselves for health management. Third, high-speed or broadband access at home is becoming more common. Fourth, individuals have now more experience with the use of the Internet and are comfortable with navigating through the millions of websites (Khechine et al., 2008).

\subsection{Electronic Healthcare (e-healthcare) Concept}

Healthcare is among the fastest-growing sectors in both developed and developing economies. E-healthcare is contributing to the explosive growth within this industry by utilizing the Internet and all its capabilities to support its stakeholders with information searches and communication processes (Mukherjee and McGinnis, 2007).

The concept of e-healthcare emerged in the early years of the twenty-first century. It is the combined use of electronic information and communication technology in the health sector for clinical and educational research and administrative purposes, both 
at the local site and across wide geographic regions. Its use has enhanced networking, facilitated global thinking, and improved healthcare on local, regional, and national levels (Rohm and Rohm, 2002).

E-healthcare is about improving consumer access to healthcare and improving healthcare service quality. This involves making adequate information available for doctors, nurses, caregivers and patients. It is also about raising operational efficiency to create patient-friendly services. The key stakeholders in the e-healthcare industry include employers, patients, providers, and health plans. Employers have a desire to analyze healthcare costs and utilization by their employees. Patients on the other hand want information about their own health. Providers too, want to save time and money by streamlining communications. Health planners want to strengthen relationships with members and providers while reducing their cost of doing business. For patients, as consumers, e-healthcare lends itself as an opportunity to change their relationship with providers and insurance companies (Mukherjee and McGinnis, 2007).

\subsection{Advantages and Disadvantages of E-health Information}

It is possible to explain increasing use of the Internet for health related purposes by many factors. Convenience of access and the potential for obtaining a variety of information about health and disease are advantages of using the Internet (Gagliardi and Jadad, 2002). The Internet currently allows patients to draw from the same knowledge base as physicians. Patients therefore become more educated and are considered 'informed consumers' (Anderson et al., 2003, Khechine et al., 2008). They are more involved in healthcare decision-making and disease prevention (Anderson et al., 2003, Coile, 2000). Also, the demand of consumers for medical information on the Internet is increasing rapidly. Another advantage of the Internet is its easy access compared to traditional information media like newspapers, television, and books.

The Internet is a very powerful vehicle for distributing health information to millions of individuals since it is interactive, user-controlled, and it provides means for communicating detailed information across a vast spectrum of topics; nevertheless, it is becoming increasingly difficult to gauge the accuracy of health information on the web (Bernhardt et al.,
2002; Erdem, 2008). The Internet is likely to remain an unregulated resource through which anyone can provide or access information. The Internet has not only increased the possibility of patients accessing information intended for health care professionals, but may also put patients in a vulnerable position as they may encounter information which is unreliable, of poor quality, difficult to understand or may not even apply to their health care needs (Dolan et al., 2004).

\subsection{E-health Information Quality}

The rapid development of health information on the Internet raises the issue of its quality (Impicciatore et al., 1997). While some authors consider that the quality of health information on the Internet is poor (Doupi and Van der Lei, 1999; Latthe et al., 2000), others feel that it is of equal value to information provided by other media (Hellawell et al., 2000, Sandvik, 1999). These contradictory results are not surprising when considered the large number and variety of sources for health information on the Internet (Benigeri and Pluye, 2003).

Once entering the domain of online health care information, the issue becomes determining the quality of the available information (Goetzinger et al., 2007). Based on the available tools that web sites provide (Wilson and Risk, 2002) and personal experience, consumers create perceptions about the overall quality of the online information.

According to relevant literature to evaluate the quality of e-health information on web sites, health care information seekers use 12 criteria that include content (quality, reliability, accuracy, scope, etc); design and aesthetics (form, interactivity, use of media, etc.); disclosure of authors, sponsors, developers; currency of information; authority of source; ease of use; user support; attribution and documentation; accessibility and availability (fee for access, navigability, functionality, etc.); links; contact addresses; credibility of sources, and confidentiality policy and intended audience (Barnes et al., 2003; Kim et al., 1999; Winker et al., 2000). Barnes et. al. (2003), argue that the most important criteria were information accuracy and source reliability. However, Bodi and Dutta (2008) imply that the evaluation of quality is a heterogeneous process that varies with the information needs of the consumer.

When evaluating e-health information on web sites, consumers express concerns regarding the use 
of unreliable research, use of technical language, believability of information, providing information to an ill-informed public, and lack of documentation (Chandra et al., 2004).

The increasing number of consumers turning to the Internet means that it is imperative that the information be worthwhile. Research shows that search productivity is important to consumers (Ratchford et al., 2003). Productivity of seeking information certainly depends on the quality of information that consumers obtain. Evidence-based information is extremely helpful for consumers within a health care context (Maloney et al., 2005). This is a problem for some web sites, which may cause consumers to evaluate the quality of the information as lower. The clarity and relevance of online health related information is vital because consumers are diagnosing themselves and even making treatment decisions based on what they find. One consumer reported as part of the qualitative study that "... information quality is obviously important especially in relation to health information; it could be potentially damaging physiologically and psychologically to receive incorrect information regarding specific conditions or symptoms" (Williams et al., 2003).

\subsection{Gender Differences in E-health Information Search}

In the literature, studies exploring gender differences in e-health information search behavior (Baker et al., 2003; Cline and Haynes, 2001; Hesse, 2005; Houston and Allison, 2002; Wagner et.al, 2001) suggest that women rather than men tend to prefer health-related sites and are more interested in health-related issues because of their care-taking roles. Wagner's study also showed that women are more aggressive than their male counterparts in searching for health-related information online for themselves and their families. In addition, they play an autonomous role when dealing with their own health or their families' health. According to results of Andreassen et al. (2007) and Ybarra and Suman's (2006) studies women are more likely to use the internet than men for e-health information.

Based on the findings of above mentioned studies, perception differences between males and females are covered in this study. Increasing interest to e-health websites bring the issue of quality into concern. This study tries to differentiate male and female e-health information seekers' perceptions regarding to the quality of e-health information.

\section{METHODOLOGY}

\subsection{Research Objectives}

The main objective of this study is to address consumer's perceptions regarding the quality of electronic health information on web sites and to understand if these perceptions differ according to gender. Identifying online health information seekers' demographic characteristics and Internet usage patterns, exploring important factors affecting consumers' Internet preference for e-health information search, are also aimed in this study. Findings of the study are thought to help health organizations and website designers in better understanding consumers' evaluations in order to improve health related information on the web.

\subsection{Research Hypothesis}

The main purpose of the study is to determine Turkish consumers' e-health information quality perception differences between males and females. Besides the main purpose, defining internet usage patterns of males and females and implying the importance of factors that affect internet preference are also aimed.

Research model in Figure 1 shows that gender is a factor that discriminate e-health information quality perceptions of males and females. Also, the differences between males and females related to Internet usage patterns and factors affecting Internet preferences are seen in the research model.

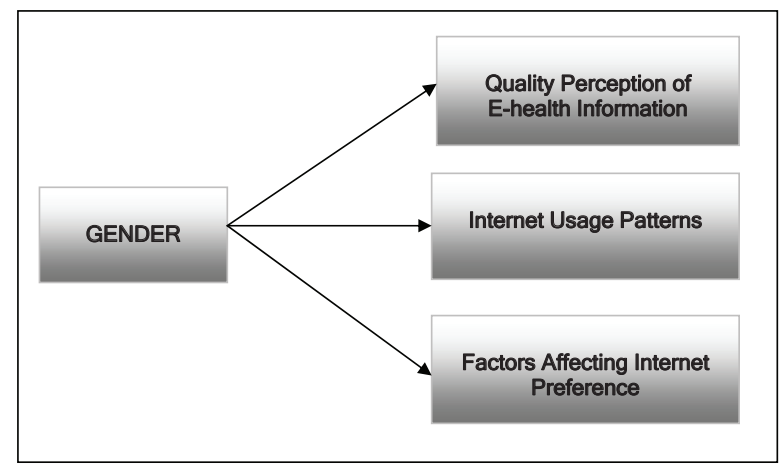

Figure 1: Research Model

Previous e-health information search literature suggests that consumers differ according to gender (Andreassen et al.,2007; Baker et al., 2003; Cline and Haynes, 2001; Hesse, 2005; Hous- 
ton and Allison, 2002; Wagner et.al, 2001; Ybarra and Suman, 2006). Considering this, it is possible to assume that males and females searching e-health information will also differ in their e-health information quality perception. Therefore, the following research hypothesis is proposed:

$\mathrm{H}_{1}$ : Consumers' e-health information quality perceptions differ according to gender.

\subsection{Measurement}

Multiple items were used to measure e-health information quality perceptions. E-health information quality perception scale has 17 items and it was adapted from Bodkin and Miaoulis (2007) and Goetzinger et al. (2007). Importance of certain factors affecting the Internet preference for e-health information search (6 items) was measured via scale adapted from Ybarra and Suman (2006).

The complete questionnaire consists of 9 questions. Some of the below aspects were questioned with answer options on a five point Likert scale (1: very important, 2: important, 3: neither important nor unimportant, 4: unimportant and 5: very unimportant; 1: strongly agree, 2: agree, 3: neither agree nor disagree, 4: disagree and 5: strongly disagree).

The questionnaire includes topics related to:

- The individual profile of the participants (Gender, Age, Education)

- Importance of certain factors affecting the Internet preference for e-health information search

- Agreement/disagreement of e-health information quality assessment criteria

- Internet usage patterns:

- If the consumer obtains information on health and illness or not

- Duration of Internet usage,

- Frequency of use

- Points of access mostly used

\subsection{Sampling and Data Collection}

The sample is made up of the Turkish people who have searched for health information online from a well known e-health website (onlinesaglik. com). The data used in this study was collected via an online survey from the same website in the first two weeks of February 2009. Participants were solicited through announcement on the website. Website utilized in the data collection is a general health site that includes topics related to all areas of medical science. Links to other health sites, web sites of medicine firms, medical product firms, medical centers, hospitals, doctors and forums are also available in the site.

To ensure that the questionnaire is well understood and to detect the existence of misinterpretation as well as any spelling and grammatical errors, face to face interview was applied to 30 people who have searched online health information. The suggestions were subsequently incorporated into the final questionnaire. The final analysis included 376 valid and complete responses out of 386 respondents.

\section{RESULTS}

\subsection{Demographics}

Demographic profile of the consumers searching e-health information on the web focuses on gender, age and education. The socio-demographic composition of the sample is summarized in Table 1. The sample comprises 218 (58\%) women and 158 men (42\%). The respondents' age ranges from 18 to over 50 years. Most of the respondents are between the age group of 26-33 (49.5\%) and followed by the age group of 18-25 (31.9\%). High School and lower grade respondents comprise 37 percent of the sample and university and over grade respondents comprise 63 percent of the sample.

Table 1: Demographic Characteristics of the Respondents

\begin{tabular}{|c|c|c|c|c|c|c|c|c|}
\hline Age & $\mathbf{n}$ & $\%$ & Education & $\mathbf{n}$ & $\%$ & Gender & $\mathbf{n}$ & $\%$ \\
\hline $18-25$ & 120 & 31.9 & Below High School & 20 & 5.3 & Female & 218 & 58.0 \\
\hline $26-33$ & 186 & 49.5 & High School & 119 & 31.7 & Male & 158 & 42.0 \\
\hline $34-41$ & 58 & 15.4 & University & 208 & 55.3 & Total & 376 & 100.0 \\
\hline $42-49$ & 7 & 1.9 & MS/Doctorate & 29 & 7.7 & & & \\
\hline 50 and over & 5 & 1.3 & Total & 376 & 100.0 & & & \\
\hline Total & 376 & 100.0 & & & & & & \\
\hline
\end{tabular}




\subsection{Descriptives}

A descriptive analysis of the e-health informatiInternet usage patterns and e-health information on-seeking consumers was undertaken to examine seeking process.

Table 2: Internet Usage Patterns of Female and Male Respondents

\begin{tabular}{|c|c|c|c|c|c|}
\hline $\begin{array}{l}\text { Duration of } \\
\text { Internet Usage }\end{array}$ & Female & Male & Frequency of Internet Usage & Female & Male \\
\hline Less than 2 years & 6.4 & 4.4 & 1-2 days a week & 0.5 & 3.2 \\
\hline $2-4$ years & 20.2 & 17.1 & 3-4 days a week & 4.1 & 1.9 \\
\hline $5-7$ years & 32.6 & 25.9 & 5-6 days a week & 12.4 & 12.7 \\
\hline $8-10$ years & 25.7 & 30.4 & Everyday & 83.0 & 82.3 \\
\hline $11-13$ years & 10.1 & 16.5 & Total & 100.0 & 100.0 \\
\hline 14 years and more & 5.0 & 5.7 & & & \\
\hline Total & 100.0 & 100.0 & & & \\
\hline $\begin{array}{l}\text { Point of Internet } \\
\text { Access }\end{array}$ & Female & Male & $\begin{array}{l}\text { Sources Used for Searching e- } \\
\text { health } \\
\text { Information }\end{array}$ & Female & Male \\
\hline From Office & 11.0 & 16.5 & $\begin{array}{l}\text { General search engines (e.g. } \\
\text { yahoo, google) }\end{array}$ & 83.5 & 84.8 \\
\hline From Home & 56.4 & 36.1 & e-health web sites & 13.3 & 10.8 \\
\hline From Office and Home & 32.6 & 46.2 & Hospital web sites & 3.2 & 3.2 \\
\hline Other & 0.0 & 1.3 & Other & 0.0 & 1.3 \\
\hline Total & 100.0 & 100.0 & Total & 100.0 & 100.0 \\
\hline
\end{tabular}

Table 2 shows Internet usage patterns of female and male consumers as percentages from the complete sample. Related to Internet usage patterns of consumers, it was found that all of the subjects surveyed have access to the Internet and did already use the Internet for gathering health related information. Most of the female respondents (32.6\%) stated that they have been using the Internet from five to seven years. Differently male respondents have been using internet from eight to ten years (30.4\%). Males are a little bit more experienced in using internet compared to females. Similarly a difference exists between males and females in point of internet access. Most of the females access the Internet from home (56.4\%) whereas males access the internet both from their office and home (46.2\%). The majority of the respondents use the Internet every day. Consumers were also asked about the sources of health information they use. The majority of females and males prefer to use their general search engines like google and yahoo as the main source of e-health information. The web sites established for giving health information are jointly the second preferred sources for information about an illness.

The importance of factors in preferring the Internet for e-health information search is also examined. As seen in Table 3, similarity is observed between females and males in the ordering of those factors. In total, the most important factor that affects consumers in preferring the Internet for health related information search is "ease of finding information" followed by "quick access to needed information", "wide availability of information", "cost free information", "opportunity in searching information about private/embarrassing topic" and "expensiveness of offline healthcare services".

Table 3: Importance of Certain Factors Affecting Internet Preference for e-health Information Search (\%)

\begin{tabular}{lrr}
\hline & Female & Male \\
\hline Finding information easily on internet & 83.0 & 81.0 \\
Quick access to needed information & 78.4 & 65.2 \\
Wide availability of information & 74.8 & 62.7 \\
Cost free information & 58.7 & 54.4 \\
Opportunity in searching information about private/embarrassing topic & 48.2 & 43.0 \\
Expensiveness of offline healthcare services & 34.4 & 29.1 \\
\hline
\end{tabular}


4.3 Reliability of the Scale Measuring E-Health Information Quality Perceptions

Respondents evaluated the information quality of e-health web sites they used in the past six months. Using a five-point scale (1: strongly agree; 5: strongly disagree), respondents evaluated 17 measures of e-health information quality (Table 4).

Table 4: E-health Information Quality Assessment Criteria

\begin{tabular}{|c|c|c|c|}
\hline & Mean & Std. Deviation & $\begin{array}{l}\text { Cronbach's } \\
\text { Alpha if Item } \\
\text { Deleted }\end{array}$ \\
\hline Useful to me & 1.50 & .64 & .958 \\
\hline Accurate & 1.71 & .74 & .956 \\
\hline Respectful - did not talk down to me & 1.77 & .81 & .956 \\
\hline Helpful - providing links to other web sites & 1.92 & .90 & .958 \\
\hline Up to date & 1.96 & .88 & .957 \\
\hline Understandable & 1.89 & .85 & .956 \\
\hline Helpful - making available articles, books, brochures & 2.03 & .96 & .957 \\
\hline Safe - my personal information is protected & 1.92 & .86 & .957 \\
\hline Not misleading & 1.97 & .86 & .957 \\
\hline Complete - the web sites provided the information I needed & 1.97 & .86 & .956 \\
\hline $\begin{array}{l}\text { Unbiased - I can form my own decisions based on the information } \\
\text { in the web site }\end{array}$ & 1.80 & .78 & .956 \\
\hline Able to offer more than one point of view & 1.87 & .79 & .956 \\
\hline $\begin{array}{l}\text { The online health information communicated important details } \\
\text { about health }\end{array}$ & 1.79 & .80 & .956 \\
\hline $\begin{array}{l}\text { The online health information provided the data necessary to estimate } \\
\text { my health status }\end{array}$ & 1.77 & .75 & .956 \\
\hline It was easy to follow the online health information & 1.79 & .76 & .956 \\
\hline $\begin{array}{l}\text { The concepts and language used by the online health information } \\
\text { made sense to me }\end{array}$ & 1.80 & .78 & .956 \\
\hline The online health information was presented clearly & 1.80 & .79 & .956 \\
\hline
\end{tabular}

The scale used to measure e-health information quality is found reliable with 0.96 Cronbach's Alpha coefficient value and there is no need to delete any of the items in order to increase Cronbach's Alpha. Besides, means of the all quality assessment items are below the neutral point, since 1 stands for "strongly agree" in the questionnaire. "Usefulness", "accuracy", and "providing data necessary to estimate health status" are the three most important quality issues.

\subsection{Gender Differences in E-Health Informa- tion Quality Perceptions}

In order to determine the differentiating e-health information quality variables between males and females, discriminant analysis with enter method was employed. This is justified on the grounds that the research was interested in a priori prediction of group membership based on the quality evaluation criteria.

Canonical discriminant function was found significant. The significance of the discriminant function was tested by using Wilks' lambda. As seen in Table 5, Wilks' lambda for function 1 is significant with value of $\mathrm{I}=0.91 ; \mathrm{p}<0.00$ and displays a canonical correlation of 0.30 . Therefore, $H_{1}$ is accepted. 
Table 5: Summary of Discriminant Analysis Results

\begin{tabular}{lccccccc}
\hline Function & Wilks' Lambda & Eigenvalue & $\begin{array}{c}\% \\
\text { of Variance }\end{array}$ & $\begin{array}{c}\text { Canonical } \\
\text { Correlation }\end{array}$ & $\begin{array}{c}\text { Chi- } \\
\text { square }\end{array}$ & df & Sig. \\
\hline 1 & 0.91 & $.10^{\mathrm{a}}$ & 100 & 0.30 & 34.96 & 17 & 0.00 \\
\hline \multicolumn{7}{l}{ a. First 1 canonical discriminant functions were used in the analysis. } \\
\hline
\end{tabular}

Table 6 contains mean values of males and females, the classification function coefficients and $F$ test statistics of the e-health information quality variables. Three statements found insignificant:
"The online health information provided the data necessary to estimate my health status", "Able to offer more than one point of view" and "Not misleading".

Table 6: Mean Comparison of Variables

\begin{tabular}{|c|c|c|c|c|}
\hline E-health Information Quality & $\begin{array}{l}\text { Female } \\
\text { Mean* }\end{array}$ & $\begin{array}{l}\text { Male } \\
\text { Mean }\end{array}$ & $\begin{array}{c}\text { Func. } \\
1\end{array}$ & $\mathbf{p}$ \\
\hline Helpful - providing links to other web sites & 1.75 & 2.15 & 0.71 & 0.00 \\
\hline Understandable & 1.75 & 2.09 & 0.64 & 0.00 \\
\hline Safe - my personal information is protected & 1.78 & 2.11 & 0.61 & 0.00 \\
\hline Up to date & 1.83 & 2.14 & 0.56 & 0.00 \\
\hline $\begin{array}{l}\text { The concepts and language used by the online health information made } \\
\text { sense to me }\end{array}$ & 1.68 & 1.96 & 0.55 & 0.00 \\
\hline Helpful - making available articles, books, brochures & 1.91 & 2.21 & 0.49 & 0.00 \\
\hline Respectful - did not talk down to me & 1.67 & 1.91 & 0.46 & 0.00 \\
\hline It was easy to follow the online health information & 1.70 & 1.91 & 0.45 & 0.00 \\
\hline $\begin{array}{l}\text { Unbiased - I can form my own decisions based on the information in the } \\
\text { web site }\end{array}$ & 1.72 & 1.92 & 0.41 & 0.01 \\
\hline Accurate & 1.63 & 1.82 & 0.40 & 0.01 \\
\hline The online health information was presented clearly & 1.72 & 1.91 & 0.38 & 0.02 \\
\hline Complete - the web sites provided the information I needed & 1.89 & 2.09 & 0.37 & 0.02 \\
\hline Useful to me & 1.44 & 1.58 & 0.35 & 0.03 \\
\hline $\begin{array}{l}\text { The online health information communicated important details about } \\
\text { health }\end{array}$ & 1.72 & 1.89 & 0.32 & 0.05 \\
\hline $\begin{array}{l}\text { The online health information provided the data necessary to estimate my } \\
\text { health status }\end{array}$ & 1.71 & 1.85 & 0.30 & 0.07 \\
\hline Able to offer more than one point of view & 1.81 & 1.96 & 0.30 & 0.07 \\
\hline Not misleading & 1.91 & 2.06 & 0.27 & 0.10 \\
\hline
\end{tabular}

According to group means, in all of the variables, females have higher e-health information quality perception than males. Females agree mostly on all of the statements. It is possible to say that, females perceive e-health information quality higher than males.
The magnitudes of the coefficients are indicators of the relative importance of each variable. The standardized canonical discriminant function coefficients are shown in Table 7. Variables that contribute most in distinguishing males and females appear in italics. 
Table 7: Standardized Canonical Discriminant Function Coefficients

\begin{tabular}{|c|c|}
\hline Standardized Canonical Discriminant Function Coefficients & $\begin{array}{c}\text { Func. } \\
1\end{array}$ \\
\hline Useful to me & -.05 \\
\hline Accurate & -.02 \\
\hline Respectful & -.21 \\
\hline Helpful-providing links to other web sites & .68 \\
\hline Up to date & -.04 \\
\hline Understandable & .48 \\
\hline Helpful - making available articles, books, brochures & -.10 \\
\hline Safe-my personal information is protected & .62 \\
\hline Not misleading & -.47 \\
\hline Complete - the web sites provided the information I needed & .09 \\
\hline Unbiased - I can form my own decisions based on the information in the web site & .31 \\
\hline Able to offer more than one point of view & -.33 \\
\hline The online health information communicated important details about health & -.10 \\
\hline The online health information provided the data necessary to estimate my health status & -.24 \\
\hline It was easy to follow the online health information & .12 \\
\hline The concepts and language used by the online health information made sense to me & .54 \\
\hline The online health information was presented clearly & -.42 \\
\hline
\end{tabular}

Standardized canonical discriminant function shows that the "Helpful - providing links to other web sites" variable $(0.68)$ is the strongest variable in differentiating the perceptions of males and females. "Safe - my personal information is protected" is the next mostly agreed variable (0.62) followed by "The concepts and language used by the online health information made sense to me" (0.54) and "Understandable" (0.48) variables.

To determine the differences between males and females on the function, group centroids (see Table 8) of the discriminant function were noted. Centroids are defined as discriminant scores for each group (male and female) on a function and indicate the distance of the group in standard deviation units from the zero mean of the discriminant function (Ahmed, 1991). If there is a great difference between the centroid of one group and the centroid of another along a discriminant function axis, then the discriminant function separates the two groups.
Table 8: Functions at Group Centroids

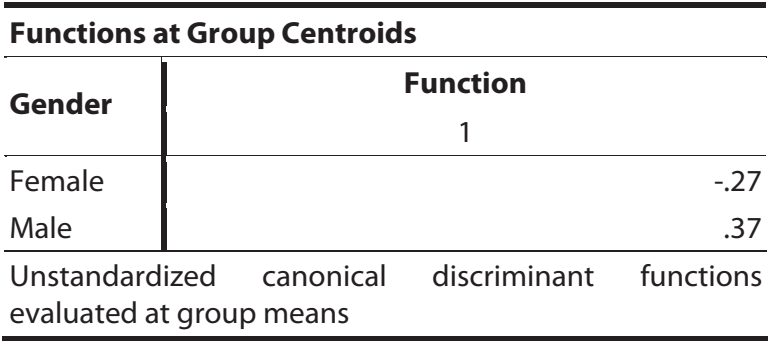

As indicated in Table 8, males' centroid (0.37) is the strongest on discriminant function 1 , followed by female $(-0.27)$.

The discriminant function, also known as a classification criterion, was estimated by measuring generalized squared distance. Table 9 shows that 62.8 percent of subjects were classified correctly by the discriminant function'. When comparing the correct classification assignments of 62.8 percent with the expected classification correctness of 50 percent, an improvement in classification was observed. This means that the e-health information quality variables used in the study successfully discriminated males and females. 
Table 9: Classification Results

\begin{tabular}{|c|c|c|c|c|c|c|}
\hline \multicolumn{7}{|c|}{ Classification Results $^{\mathrm{a}}$} \\
\hline & & \multicolumn{5}{|c|}{ Predicted Group Membership } \\
\hline & & Gender & Female & Male & & Total \\
\hline \multirow{4}{*}{ Original } & \multirow{2}{*}{ Count } & Female & 176 & & 42 & 218 \\
\hline & & Male & 98 & & 60 & 158 \\
\hline & \multirow{2}{*}{$\%$} & Female & 80.7 & & 19.3 & 100.0 \\
\hline & & Male & 62.0 & & 38.0 & 100.0 \\
\hline
\end{tabular}

a. $62.8 \%$ of original grouped cases correctly classified.

\section{CONCLUSION}

Exploring the perceptual differences of males and females in evaluating electronic health information quality is the main purpose of this study. Results of the study indicated differences between males and females' e-health information quality perceptions. Research findings showed that female respondents who participated in this survey perceive e-health information quality higher than males, but some of the statements differentiate males and females more, compared to others. For instance, females perceive online health information more helpful, because the web site provides links to other web sites that gives further information. Also, perception of online health information's safety differs between genders. Females perceive e-health information safer than males. Females don't perceive any risk about sharing their personal information. The concepts and language used by the health information web sites makes more sense to female respondents. In addition, female respondents found e-health information more understandable.

Research findings revealed that males perceive e-health information quality lower than females. This could suggest that males and females perceive e-health information in different ways. One possible explanation of this situation may be that females usually assume more responsibility for the healthiness and well-being of their families, therefore they become more interested than males in actively seeking health information. This makes females more interested in online health information search and they become more involved in quality evaluation of e-health web sites than males.

Besides the main purpose, this study tried to explore online health information seekers' demographic characteristics, identify important factors affecting their Internet preference for e-health information search and determine their Internet usage patterns.
Examination of demographics showed that females, youngest and educated consumers are mostly represented in this study. The most important factors affecting Internet preference for e-health information are reported as easiness, quickness and being costfree compared to other channels as expected. Internet usage patterns of the respondents in searching e-health information show that consumers mostly prefer general search engines like google and yahoo.

\section{LIMITATIONS, IMPLICATIONS AND FUTURE RESEARCH}

As with any research, there were limitations in design and implementation that affect generalization assumptions among other interpretation outcomes. Although online data collection fits well with the current study, there is some questions about its representativeness. Having been conducted in one e-health web site, the data generated may not be representative of the whole. The method of sampling also created a rather homogeneous pool of participants. Future research extending the present study should recruit a larger, more diverse sample to overcome such limitations and broaden interpretation. Also, current study focused mostly on e-health quality perception differences between males and females, it excluded other differences between demographics.

The underlying implications of the results of this study are important for web site designers and healthcare professionals. Web site designers should focus on providing easy to understand and up to date information that males can use along with increasing their knowledge about the health topic in question. Besides, links should be suggested to other health related websites. Web site providers should also focus on increasing their safety standards in order to convince males. 
This study has provided an initial attempt to understand which constructs contribute to consumers' quality perceptions in electronic health information search in Turkey and tries to determine whether males and females differ in their quality perceptions. It may also be beneficial to segment consumers based on their health information search interests in order to determine whether their search patterns and resulting satisfaction affect their quality perception besides their gender.

\section{END NOTE}

"The classification accuracy should be at least one-fourth greater than that achieved by chance. For example, if chance accuracy is 50 percent, the classification accuracy should be 62.5 percent $(62.5 \%=1.25 \times 50 \%)^{\prime \prime}$ (Hair et al.,1998 p.269).i.

\section{REFERENCES}

Ahmed, Z. U. (1991) "Marketing Your Community: Correcting a Negative Image" The Cornell Hotel and Restaurant Administration Quarterly, 31(4): 24-27.

Akerkar, S. M., and Bichile, L. S. (2004) "Health Information on the Internet: Patient Empowerment or Patient Deceit?" Indian Journal of Medical Sciences, 58(8): 321-326.

Anderson J. G., Rainey, M. R., and Eysenbach, G. (2003) "The Impact of Cyberhealthcare on the Physician-patient Relationship" Journal of Medical Systems, 27(1): 67-84.

Andreassen, H. K., Bujnowska-Fedak, M. M., Chronaki, C. E., Dumitru, R. C., Pudule, I., Santana, S., Voss, H., and Wynn, R. (2007): "European Citizens' Use of E-health Services: A Study of Seven Countries" BMC Public Health, 7(53): $1-7$.

Baker L, Wagner, T.H., Singer, S. and Bundorf, M.K. (2003) "Use of the Internet and E-mail for Health Care Information" The Journal of the American Marketing Association, 289:2400-6.

Barnes, M. D., Penrod, C., Neiger, B. L., MerrilL, R. M., Thackeray, R., Eggett, D. L., and Thomas, E. (2003) "Measuring the Relevance of Evaluation Criteria Among Health Information Seekers on the Internet" Journal of Health Psychology, 8(1): 71-82.

Benigeri, M. and Pluye, P. (2003) "Shortcomings of Health Information on the Internet" Health Promotion International, 18(4): 381-386.

Bernhardt, J. M., Lariscy, R. A. W., Parrott, R. L., Silk, K. J. and Felter, E. M. (2002) "Perceived Barriers to Internet-Based Communication on Human Genetics" Journal of Health Communication, 7: 325-340.

Bodie, G. D. and Dutta, M. J. (2008) "Understanding Health Literacy for Strategic Health Marketing: Ehealth Literacy, Health Disparities, and the Digital Divide" Health Marketing Quarterly, 25(1): 175-203.

Bodkin, C., and Miaoulis, G. (2007) "E-Health Information Quality and Ethics Issues: An Exploratory Study of Consumer Perceptions" International Journal of Pharmaceutical and Healthcare Marketing, 1(1): 27- 42.

Chandra, A., Sikula, A. JR., and Paul, D. P. (2004) "III. Digital Marketing: Ethical Considerations in the Marketing of E-Health Products" International Journal of Medical Marketing, 4(2): 110-118.
Cline, R. J. and Haynes, K. M. (2001) "Consumer Health Information Seeking on the Internet: The state of the art", Health Education Research, 16, 671-692.

Coile, R. C. Jr. (2000) "E-Health: Reinventing Healthcare in the Information Age" Journal of Healthcare Management, 45(3): 206-210.

Cudore, B. A., and Bobrowski, P. E. (2003) "How Effective Are Healthcare Web Sites for Marketers?" Marketing Health Services, 23(3): 37-41.

Dickerson, S., Reinhart, A. M., Feeley, T. H., Bidani, R., Rich, E., Garg, V. K., and Hershey, C. O. (2004) "Patient Internet Use for Health Information at Three Urban Primary Care Clinics" Journal of the American Medical Informatics Association, 11(6): 499-504.

Dolan, G., Iredale, R., Williams, R., and Ameen, J. (2004) "Consumer Use of the Internet for Health Information: A Survey of Primary Care Patients" International Journal of Consumer Studies, 28(2): 147-153.

Doupi, P., and Van Der Lei, J. (1999) "R-X Medication Information for the Public and the www: Quality Issues" Medical Informatics and the Internet in Medicine, 24: 171-179.

Dumitru, R. C., Bürkle, T., Potapov, S., Lausen, B., Wiese, B., and Prokosch, H. U. (2007) "Use and Perception of Internet for Health Related Purposes in Germany: Results of A National Survey" International Journal of Public Health, 52: 275-285.

Erdem, S. A. (2008) "Healthcare Marketing on the Web: Moving Forward Toward More Interactive Practices" Health Marketing Quarterly, 24(1/2): 35 -49.

Eysenbach, G., and Diepgen, T. L. (1998) “Towards Quality Management of Medical Information on the Internet: Evaluation, Labelling, and Filtering of Information" British $\mathrm{Me}$ dical Journal, 317: 1496-1500.

Eysenbach, G., and Diepgen, T. L. (1999) "Patients Looking for Information on the Internet and Seeking Tele Advice: Motivation, Expectations, and Misconceptions As Expressed in E-Mails Sent To Physicians" Archives of Dermatology, 135: 151-156.

Gagliardi, A., and Jadad, A. R. (2002) "Examination of Instruments Used to Rate Quality of Health Information on the Internet: Chronicle of A Voyage With An Unclear Destination" British Medical Journal, 324: 569-573. 
Goetzinger, L., Park, J. Lee, Y.J., and Widdows, R. (2007) "Value-Driven Consumer E-Health Information Search Behavior" International Journal of Pharmaceutical and Healthcare Marketing, 1(2), 128-142.

Gruca, T. S. and Wakefield, D. S. (2004) "Hospital Web Sites: Promise and Progress" Journal of Business Research, 57(9): 1021-1025.

Hair, J. F., Anderson, R. E., Tatham, R. L. and Black, W. C. (1998) Multivariate Data Analysis, Fifth Edition, Upper Saddle River, New Jersey, Prentice Hall.

Hellawell, G. O., Turner, K. J., Le Monnier, K. J., and Brewster, S. F. (2000) "Urology and the Internet: An Evaluation of Internet Use by Urology Patients and of Information Available on Urological Topics" BJU International, 86: 191-194.

Hesse, B.W. (2005) "Trust and Sources of Health Information" Archives of International Medicine, 165: 2618-24.

Houston, T.K., Allison, J.J. (2002) "Users of Internet Health Information: Differences by Health Status" Journal of Medical Internet Research, 165:2618-24.

Hussain, N, Agyeman, A, and Das Carlo, M. (2004) "Access, Attitudes, and Concerns of Physicians and Patients toward E-Mail Use in Health-Related Communication" Texas Medicine, 100(3): 50-57.

Impicciatore, P., Pandolfini, C., Casella, N., and Bonati, M. (1997) "Reliability of Health Information for the Public on the World Wide Web: Systematic Survey of Advice on Managing Fever in Children at Home" British Medical Journal, 314: 1875-1879.

Khechine, H, Pascot, D, and Prémont, P. (2004a) "Details about the Use of the Internet for Health Information" Information Systems in an E-World, September: 102-116.

Khechine, H., Pascot, D., and Prémont, P. (2004b) "Information from the Internet and Health" International Journal of Computers, Systems and Signals; 5(1): 58-66.

Khechine, H., Pascot, D., and Prémont, P. (2008) "Use of Health-Related Information from the Internet by EnglishSpeaking Patients" Health Informatics Journal, 14(1): 17-28.

Kim, P., Eng, T. R., Deering, M. J., and Maxfield, A. (1999) "Published Criteria for Evaluating Health Related Web Sites: Review" British Medical Journal, 318: 647-649.

Latthe, M., Latthe, P. M., and Charlton, R. (2000) "Quality of Information on Emergency Contraception on the Internet" British Journal of Family Planning, 26: 39-43.

Lueg, J. E., Moore, R. S., and Warkentin, M. (2003) "Patient Health Information Search: An Exploratory Model of Web-Based Search Behavior" Journal of End User Computing, 15(4): 49-61.

Maloney, S., Ilic, D., and Green, S. (2005) "Accessibility, Nature and Quality of Health Information on the Internet: A Survey on Osteoarthritis" Rheumatology; 44(33): 382-385.

Morahan-Martin, J. M. (2004) "How Internet Users Find, Evaluate, and Use Online Health Information: A CrossCultural Review" Cyberpsychology \& Behavior, 7(5): 497510.

Mukherjee, A., and Mcginnis, J. (2007) "E-Healthcare: An Analysis of Key Themes in Research" International Journal of Pharmaceutical and Healthcare Marketing, 1(4): 349363.
Nustad, J., Adams, T., and Moore, M. (2008) "Health Information Sources Accessed by College Females: Differences Between Body-Image Distorted and Non-Body-Image Distorted” Health Marketing Quarterly, 25(3): 241-253.

Office of National Statistics. (2003) "Family Spending: A Report on the 2001-2002 Expenditure and Food Survey", London: Office for National Statistics.

Paris, J., and FerrantI, J. (2001) "The Changing Fact of Medicine: Health Care on the Internet” Journal of Perinatology, 21(1): 34-39.

Ratchford, B. R., Lee, M., and Talukdar, D. (2003) "The Impact of the Internet on Information Search for Automobiles" Journal of Marketing Research, 40(2): 193-209.

Risk, A., and Petersen, C. (2002) "Health Information on the Internet: Quality Issues and International Initiatives" Journal of the American Medical Association, 287: 2713-2715.

Rohm, B. W. T., and Rohm, C. E. T. Jr. (2002) "A Vision of the E-Healthcare Era" International Journal of Healthcare Technology and Management, 4(1-2): 87-92.

Sandvik, H. (1999) "Health Information and Interaction on the Internet: A Survey of Female Urinary Incontinence" British Medical Journal, 319: 29-32.

Shuyler, K. S., and Knight, K. M. (2003) "What Are Patients Seeking When They Turn to the Internet? Qualitative Content Analysis of Questions Asked by Visitors To An Orthopaedics Web Site" Journal of Medical Internet Research, 5(4): 24-34.

TUIK, Turkish Statistical Institute News Bulletin, (2009) "Household Information Technology Usage Study Results”.

TUIK, Turkish Statistical Institute News Bulletin, (2007) "Household Information Technology Usage Study Results”.

Wagner, T. H., Hu, T. W., Hibbard, J. H. (2001) “The Demand for Consumer Health Information" Journal of Health Economics, 20: 1059-1075.

Williams, P., Huntington, P., and Nicholas, D. (2003) "Health Information on the Internet: A Qualitative Study of Nhs Direct Online Users” Aslib Proceedings, 55(5/6): 304-312.

Wilson, P., and Risk, A. (2002) "How To Find the Good and Avoid the Bad Or Ugly: A Short Guide to Tools for Rating Quality of Health Information on the Internet" British Medical Journal, 324(7337): 598-602.

Winker, M. A., Flanagin, A., Chi-Lum, B., White, J., Andrews, K., and Kennett, R. L. (2000) "Guidelines for Medical and Health Information Sites on the Internet: Principles Governing AMA Web Sites" Journal of the American Medical Association, 283: 1600-1606.

Ybarra, M. L., and Suman, M. (2006) "Help Seeking Behavior and the Internet: A National Survey" International Journal of Medical Informatics, 75: 29-41. 